\title{
Removing Nasal Packing in Epistaxis: \\ What to Do in the Case of an Undeflatable Foley Catheter Balloon
}

\author{
Fernando Pena Gaspar-Sobrinho ${ }^{1}$ Mariana D. Moreira ${ }^{1}$ Cibele G. Bicalho ${ }^{1}$ Hélio A. Lessa ${ }^{1}$ \\ ${ }^{1}$ Department of Otorhinolaryngology, University Hospital Professor \\ Edgar Santos, Universidade Federal da Bahia, Salvador/BA, Brazil \\ Address for correspondence Fernando P. Gaspar-Sobrinho, MD, Av. \\ Augusto Vianna, S/N, CEP 41150-050, Salvador/BA, Brazil \\ (e-mail: drgaspar@uol.com.br). \\ Int Arch Otorhinolaryngol 2014;18:80-82.
}

\begin{abstract}
Introduction Undeflatable Foley catheter balloons adapted for use as nasal packing in epistaxis represent a possible complication.

Case Reports We report on three cases in which Foley catheter balloons adapted for use as posterior nasal packing in epistaxis failed to deflate. In one patient, deflation was achieved by simply using the fingertips to massage the segment of the catheter collapsed by the fixation device. In the second case, the Foley balloon was removed by the oral route after sectioning the catheter. In the third patient, the Foley catheter was successfully deflated after sectioning. Discussion The probable causes of the undeflatable balloons in these cases were a blockage or lumen collapse of the balloon or a malfunction in the valve system. Although no definitive method has been established for dealing with this complication, the options proposed are the following: manipulation to restore the permeability of the

Keywords

- epistaxis

- catheters

- nose diseases segment of the catheter collapsed by the fixation device, if this is the case; sectioning the catheter or inserting a stiletto catheter; bursting the balloon; or removing it by the oral route. The latter option is apparently the most appropriate for the otolaryngologist in cases unrelated to simple collapse caused by the fixation device.
\end{abstract}

\section{Introduction}

Urologists are occasionally required to remove a Foley catheter in situations in which the balloon inserted into the bladder cannot be deflated. Various techniques have been described for this complication.

Because the Foley urinary catheter can be adapted for use as posterior nasal packing in epistaxis, the otolaryngologist should be able to identify and treat any complications related to its use. A review of the pertinent literature revealed only one publication on the Foley catheter adapted for use in epistaxis in which the balloon failed to deflate. ${ }^{1}$

In the present report, three cases were analyzed in which the Foley catheter adapted for use as posterior nasal packing failed to deflate. Furthermore, based on their own experience, the authors propose an algorithm for dealing with this complication.

received

October 31, 2011

accepted

DOI http://dx.doi.org/

$10.1055 / \mathrm{s}-0033-1351672$. ISSN 1809-9777.

\section{Literature Review}

-Fig. 1 shows a cross section of the principal Foley catheter tube with the lumen used to drain urine from the bladder and the balloon channel.

The factors associated with undeflatable Foley catheter balloons are generally related to malfunctions in the catheter valve system, blockages in the balloon channel caused by foreign objects (either saline solution crystals or blood clots), prolonged catheterization, or tube collapse resulting from compression. ${ }^{2,3}$ This latter mechanism is particularly relevant in otorhinolaryngology, because the instruments used to secure the Foley catheter in the nose may constrict and cause a lumen collapse in the Foley catheter.

Various methods have been described for removing the Foley balloon from the bladder: sectioning the Foley catheter, ${ }^{2}$ ultrasound-guided percutaneous puncture, ${ }^{3}$ insertion of

Copyright (c) 2014 by Thieme Publicações License terms Ltda, Rio de Janeiro, Brazil 


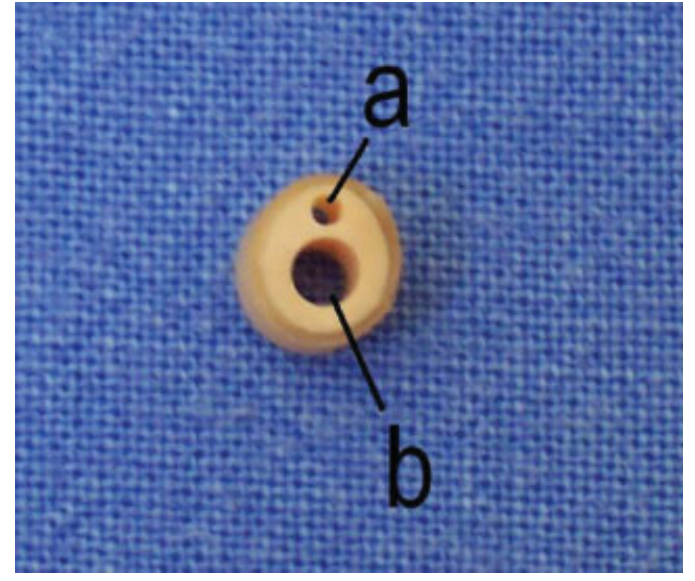

Fig. 1 Cross section of the Foley catheter: note the channels for the balloon (a) and for bladder drainage (b).

a stiletto to unblock the catheter, ${ }^{4}$ injection of ether or acetone into the balloon channel, ${ }^{5}$ and bursting the balloon with the use of endoscopy for visualization. ${ }^{6}$

In the case of an undeflatable Foley catheter following treatment of epistaxis, Choy et al removed the Foley balloon from the nasopharynx through the patient's mouth using Lore optical nasopharyngeal biopsy forceps associated with posterior rhinoscopy performed using a 70-degree Hopkins telescope. $^{2}$

\section{Case Reports}

\section{Case 1}

A 58-year-old man admitted to hospital with posterior epistaxis was treated for 3 days with anteroposterior nasal packing using gauze and a $14 \mathrm{~F}$ Foley catheter with a $30-\mathrm{mL}$ balloon.

\section{Case 2}

A 46-year-old man with posterior epistaxis was submitted to anteroposterior nasal packing using gauze and a $12 \mathrm{~F}$ Foley catheter with a 30-mL balloon, which was maintained in place for 4 days.

\section{Case 3}

A 55-year-old man was submitted to anteroposterior nasal packing using lubricated gauze and a $12 \mathrm{~F}$ Foley catheter with a 30-mL balloon, which remained in place for 3 days.

In all three cases, we used 8 to $12 \mathrm{~mL}$ of water to inflate the Foley catheter. The valve of the parenteral infusion device was used to secure the Foley catheter. ${ }^{3}$ During removal of the nasal packing, it was found that the Foley catheter balloons, adapted for use as posterior nasal packing, would not deflate. A short segment of the main catheter tube had collapsed at the site at which it was secured by the valve of the fixation device. In case 1 , the blocked segment was massaged for less than a minute before the water began to flow out and the balloon deflated (-Fig. 2). In cases 2 and
3, massaging the principal tube of the Foley catheter failed to restore the permeability of the catheter ( - Fig. 3 ). In case 2 , the tube was then sectioned upstream of the segment compressed by the fixation device; however, the balloon still failed to deflate. Finally, the decision was made to remove it through the patient's mouth. Following topical anesthesia of the pharynx using $10 \%$ lidocaine, the distal portion of the Foley catheter was identified and grasped, and its balloon was removed through the oral route using Kelly forceps. In case 3, a decision was made to puncture the balloon using a Takahashi forceps, viewed under nasal endoscopy. There was no recurrence of bleeding in any of these cases.

\section{Discussion}

Evaluation of case 1 suggests that collapse of the lumen of the Foley catheter may be resolved by simple manipulation of the blocked segment.

Choy et al reported the only published case of an undeflatable Foley catheter balloon following use as nasal packing in which a clip was used to secure the catheter. ${ }^{2}$ These authors reported that damage to the catheter due to the pressure caused by the clip was responsible for obstructing the Foley catheter.

When adapted for use as nasal packing, the Foley catheter must be adequately secured to prevent its displacement, and several instruments have been proposed for this purpose. ${ }^{7-10}$ Some, such as the umbilical cord clamp, function by compressing the catheter. We use the valve of the parenteral infusion device for this purpose, and results have been satisfactory in preventing lesions to the nasal wings and nasal columella. ${ }^{11}$

If massaging the tube of the Foley catheter does not deflate the balloon, the tube can be sectioned upstream of the segment compressed by the fixation device. If the problem persists after the catheter has been sectioned, as seen in cases 2 and 3, the problem is probably a malfunction in the catheter or elsewhere, unrelated to the way in which the instrument was secured inside the nose.

It is possible to burst the Foley catheter balloon inside the nasopharynx using endoscopy and a perforating instrument. Nevertheless, bursting the Foley catheter balloon may release free fragments of latex. ${ }^{12}$

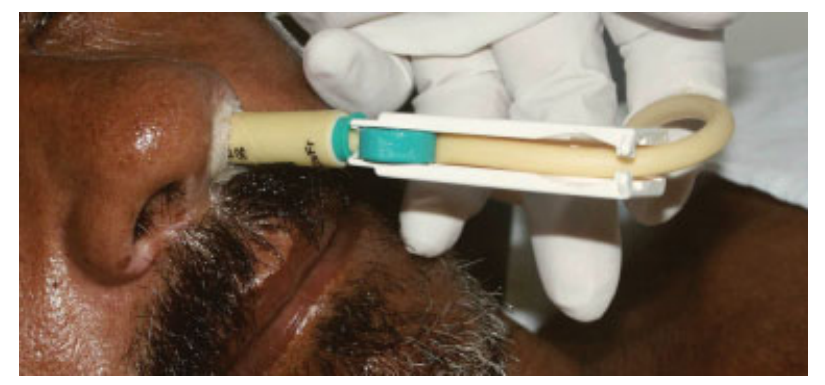

Fig. 2 Securing the Foley catheter in the nose using the valve of the device (a parenteral infusion set). 
82 Removing Nasal Packing in Epistaxis Gaspar-Sobrinho et al.

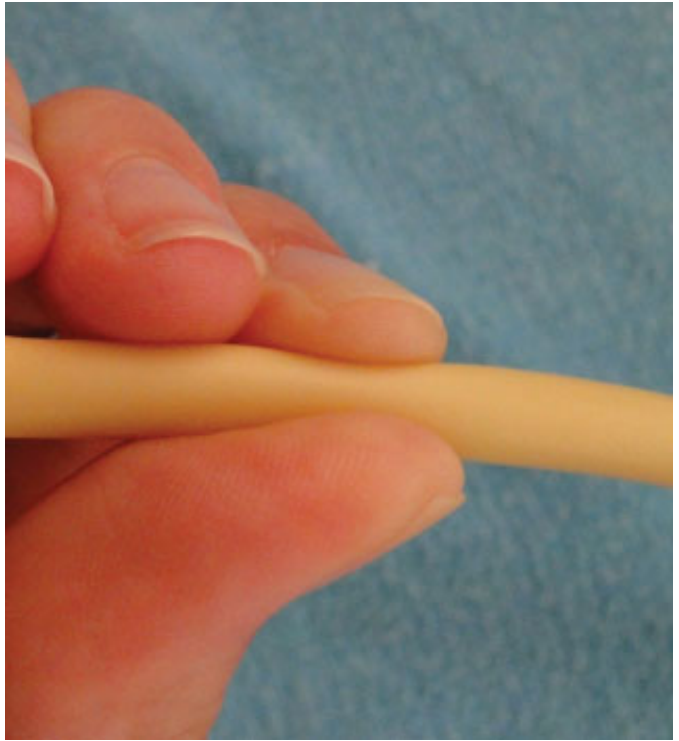

Fig. 3 Squeezing the Foley catheter with the fingertips may restore permeability of the segment of tube collapsed by the device used to secure the catheter in the nose.

Bursting a Foley balloon containing liquid inside the nasopharynx may theoretically result in bronchoaspiration; however, the volume of liquid used to inflate the balloon is small, ${ }^{13}$ and for anatomical reasons it is more likely to reach the oropharynx in the form of posterior drainage.

According to Choy et al, the methods recommended in urology for this complication are expensive and require specific material. Therefore, the most convenient alternative for the otolaryngologist is to keep the Foley balloon inflated in the nasopharynx and attempt to remove it orally, a task that is made easier with the use of telescopic vision. $^{2}$

To prevent obstruction of the tube of the Foley catheter, the use of water rather than saline solution is preferable.

\section{Conclusion}

If the Foley catheter used in nasal packing for the treatment of epistaxis fails to deflate using the normal technique, we suggest the following steps:
1. Identify the segment that has been compressed by the fixation device or any folds in the catheter and manipulate them using the fingertips.

2. If the problem persists, section the tube to remove the compressed or folded segment.

3. If the fluid is not eliminated through the sectioned proximal extremity, remove the catheter and its balloon through the oral route with the aid of forceps or after puncturing the balloon.

\section{References}

1 Stemm RA. Complications of nasal packing. Ear Nose Throat J 1981;60:461-462

2 Choy ATK, John DG, van Hasselt CA. Posterior epistaxis and the undeflatable Foley's urinary catheter balloon. J Laryngol Otol 1993;107:142-143

3 Gaspar-Sobrinho FP, Lessa HA. Fixação da sonda de Foley no tratamento da epistaxe posterior e prevenção de lesões à asa do nariz. Arq Otorrinolaringol 2003;7:272-276

4 Pohl FF, Petroianu A. Tubos, sondas e drenos. 1st ed. Rio de Janeiro, Brazil: Guanabara Koogan; 2000

5 O'Flynn KJ, Thomas DG, Hardy A. Harpoon device for removal of obstructed balloon catheters. Br J Urol 1992;69:217

6 Moffat LEF, Teo C, Dawson I. Ultrasound in management of undeflatable Foley catheter balloon. Urology 1985;26:79

7 Addonizio JC, Sayegh N, Sayegh N. Management of undeflatable Foley catheter balloon. Urology 1982;19:318

8 Conn IG. Undeflatable Foley catheter balloons: a simple solution. Urology 1987;30:275

9 Saxena A, Khanna S, Vohra BK. Endoscopic management of the undeflatable Foley catheter balloon. Br J Urol 1992;69:217-218

10 Gaspar-Sobrinho FG, Damasceno EP, Lessa HA, do Valle AC. Instrumentos para fixação da sonda de Foley no tratamento da epistaxe posterior e prevenção de lesões à asa do nariz. In: Anais do III Congresso Triológico de Otorrinolaringologia; 2003; Rio de Janeiro, Brazil

11 Gaspar-Sobrinho FP, Damasceno EP, Esperidião AC, Lessa HA. Efeito de lubrificantes sobre a integridade da sonda de Foley e implicações no tamponamento nasal para epistaxe. Rev Bras Otorrinolaringol (Engl Ed) 2004;70:7-10

12 Chrisp JM, Nacey JN. Foley catheter balloon puncture and the risk of free fragment formation. Br J Urol 1990;66:500-502

13 McFerran DJ, Edmonds SE. The use of balloon catheters in the treatment of epistaxis. J Laryngol Otol 1993;107:197-200 